\title{
Suporte de identificação e enfrentamento de situações-problema (Siesp)
}

Pedro Paulo Costallat Bruno

\section{Introdução}

A Metodologia de Sistemas Flexíveis (MSF) e metodologias como a Spiral Dynamics, Systems Intervention Methodology, Value Systems Theory, conforme apontam Rubstein-Montano et al. (2001), ou a Managing from Clarity Methodology sugerida por Ritchie-Dunham e Rabbino (2001), adotam o pensamento sistêmico ${ }^{1}$. As abordagens sistêmicas, a exemplo dessas, justificam-se devido ao crescimento da complexidade das organizações, que necessitam melhorar a capacidade de compreender e enfrentar adequada e oportunamente situações e problemas também cada vez mais complexos (KASPER, 2006) e difíceis de perceber antes de se agravarem, impondo conseqüências indesejáveis irreversíveis.

Além das dificuldades relacionadas com as complexas características de autoorganização, interação, eventos aleatórios, adaptação e evolução das organizações contemporâneas (DANN e BARCLAY, 2006), duas outras razões tratadas a seguir justificam recorrer ao Suporte de Identificação e Enfrentamento de 
Situações-Problema (Siesp) existentes implícita ou explicitamente, de um modo geral, nos contextos das organizações. Mais especificamente, no contexto dos sistemas de informação organizacional ${ }^{2}$, incluindo o das agências reguladoras, a exemplo do da Agência Nacional de Energia Elétrica (Aneel) enfocado aqui.

A primeira das razões, a de natureza descritiva, é ampliar conhecimentos sobre esse contexto, distinguir e enquadrar uma situação, de fato, problemática. A orientação dada nesse sentido pelo Siesp acaba por ajudar a visualizar informações ${ }^{3}$ relevantes sobre essa situação antes não detectada, permitindo assim distingui-la de outras situações desimportantes que com ela podem ser confundidas. A expansão do conhecimento que daí emerge propicia capacidade de distinguir as causas dos efeitos, as atividades intermediárias das finalísticas, as partes do todo, o essencial do acessório, as situações importantes das outras comuns.

A segunda razão, a de natureza prescritiva, complementar à primeira, reside também em expandir conhecimentos. A diferença é que neste caso se busca descobrir conhecimentos a serem usados para enfrentar a situação-problema. Isto é, descobrir, obter, gerenciar recursos informacionais ${ }^{4}$ e promover o reconhecimento do domínio técnico necessário para agir, provocando mudanças que sejam eficazes no enfrentamento da situaçãoproblema.

Conhecimentos classificados de várias formas, compartimentados consciente ou inconscientemente em silos funcionais, áreas especializadas, grupos, hierarquias ou, ainda, retidos por indivíduos isoladamente, assumem valor no caso do seu aproveitamento extrapolar esses limites para que seu uso favoreça a organização como um todo.
Desse modo, os conhecimentos tendem a adicionar valor efetivo à corporação. Suportes para a criação, expansão, orientação e o melhor aproveitamento do fluxo e do estoque dos conhecimentos são recursos que ajudam comunidades de prática ${ }^{5}$, processos e subprocessos organizacionais. Uma classificação desses conhecimentos é mostrada no Quadro 1.

De um lado, a perspectiva descritiva enfatiza a importância de explicitar, codificar e disseminar conhecimentos sobre um contexto específico e aproveitar enfaticamente o conhecimento do tipo declarativo (know-what) para distinguir e compartilhar o que é importante. Por exemplo, uma situação-problema. De outro lado, a perspectiva prescritiva destaca o procedural knowledge (know-how). Isto é, os modos de conversão do conhecimento, os instrumentos que facilitam essa conversão e os modelos de gestão estratégica da informação (frameworks) que ajudam a enfrentar racional, organizada e eficazmente a situação-problema.

Ambas as perspectivas se complementam para esclarecer a importância de compreender, incluir, dominar e utilizar conhecimentos, induzindo-os a transitarem por entre fronteiras formal (processos e subprocessos) e informalmente (comunidades de prática) estabelecidas dentro da organização. Fronteiras essas que podem inibir em vez de incentivar o compartilhamento do conhecimento (Novak, 2007), bem como o seu aproveitamento.

A partir desse esclarecimento, deixase de confundir decisão com ação. A ação é conseqüência da própria decisão ao lado da escolha, da responsabilidade e da legitimidade para agir (Brunsson, 2007). Os conhecimentos, notadamente o conseqüencial (know-consequence), tendem a fluir mais facilmente, a serem ampliados e, por 


\section{Quadro 1: Classificação dos conhecimentos}

\begin{tabular}{l|l}
\hline Dimensão do conhecimento & $\begin{array}{l}\text { Tácito e explícito; cultural. } \\
\text { Codificado e não codificado; disseminado ou público e não } \\
\text { disseminado ou privado. }\end{array}$ \\
\hline Percepção do conhecimento & $\begin{array}{l}\text { Como estado mental; objeto; processo; acesso a informações; } \\
\text { representação de conteúdos informacionais; capacidade. }\end{array}$ \\
\hline Tipo & $\begin{array}{l}\text { Individual e social; declarativo (know-what, know-about, knowledge } \\
\text { about knowledge); procedural (know-how); causal (know-why); condi- } \\
\text { cional (know-when); relacional (know-who, know-with); situacional } \\
\text { (know-where); conseqüencial (know-consequence). }\end{array}$ \\
\hline Processo & $\begin{array}{l}\text { Geração (criação, aquisição) e aplicação (integração, } \\
\text { compartilhamento, replicação, armazenamento, mensuração, } \\
\text { identificação). }\end{array}$ \\
\hline Importância estratégica & $\begin{array}{l}\text { Escassez, relevância, dificuldade de transmitir, custo elevado, } \\
\text { dificuldade de imitar, aumento do valor com o uso. }\end{array}$ \\
\hline Sistema de gestão & \begin{tabular}{l} 
Informação aplicada à gestão do conhecimento organizacional. \\
\hline Modo de conversão
\end{tabular} \\
\hline Ciclo & $\begin{array}{l}\text { Socialização, externalização, combinação, internalização. } \\
\text { contextualização, aquisição/aplicação e atualização. }\end{array}$ \\
\hline Modelo de gestão & $\begin{array}{l}\text { Epistemologia organizacional; espiral do conhecimento; Sense- } \\
\text { making; building and using knowledge; I-Space; complex adaptative } \\
\text { system. }\end{array}$ \\
\hline
\end{tabular}

Fonte: Polanyi (1967); Boisot, 1995 (Apud Choo, 2003). Alavi e Leidner, 2001. Brunsson, 2007. Grant, 2005. Forcadell e Guadamillas, 2002. Nonaka, 1994. von Krogh e Roos, 1995; Nonaka e Takeuchi, 1995; Choo, 1998; Wiig, 1993; Boisot, 1998; Beer, 1981; Bennet e Bennet, 2004 (Apud Dalkir, 2005).

conseguinte, aproveitados durante a conversão das decisões em ações, ocasionando mudanças desejáveis.

É preciso destacar que situaçãoproblema difere de problema. A situaçãoproblema se modifica com o tempo devido a alterações em suas complexas ramificações, as quais não se revelam imediata e claramente, provocando ambigüidades, equivocalidades e incertezas. Isso implica, respectivamente, a permanente necessidade de expandir o conhecimento sobre a situação crítica (know-what), o conhecimento sobre como enfrentá-la (know-how) e o conhecimento sobre as conseqüências desse enfrentamento (know-consequence). O problema, diversamente, é um fenômeno evidente logo percebido. Sua detecção pode ser programada assim como sua resolução pode ser automatizada. Basta definir um script, escrever um algoritmo ou definir parâmetros para que a máquina seja acionada com a finalidade de resolvê-lo ou de disparar alertas em face da ocorrência do problema.

O enfrentamento de situaçõesproblema, de outro modo, requer reflexão constante. Impõe o emprego do intelecto e a assunção dos custos relativos ao desenvolvimento contínuo destas três capacidades:

- Analítica de detectar, coletar, recuperar, compartilhar e facilitar o acesso às 
informações que permitam compreender o contexto e esclarecer qual é a situaçãoproblema.

- Sintética de selecionar, sumarizar, filtrar, reter, classificar, atualizar e arquitetar as informações confiáveis com o objetivo de bem informar as decisões e representar o conhecimento qualificado sobre como enfrentar a situação-problema.

- Pragmática de aproveitar o conhecimento para converter decisões em ações cujas consequências são desejáveis.

Ao requerer e convergir essas três capacidades, relacionar o saber teórico com o prático, aceitar o pensamento divergente e empregar técnicas, tecnologias e formas de resolução de disputas (negociação, mediação e arbitragem) que variam constantemente, os suportes e as metodologias que tratam da complexidade das situações-problema produzem oportunidades para compreender e intervir adequada e oportunamente em contextos específicos como o dos sistemas de informação. Sobretudo, devido a três razões.

A primeira é porque, ao intencionar levantar informações e expandir conhecimentos destinados a identificar e esclarecer situações-problema, as metodologias e os suportes usados para balizar decisões e ações destacam o ponto de vista multidisciplinar da monitoração ambiental (MA). Essa disciplina, sob o aspecto da teoria ou da prática gerencial, busca obter, interpretar, avaliar, comunicar e utilizar informações (BARBOSA, 1997), credenciando as organizações que a adotam a monitorarem o ambiente e a ampliarem a chance de êxito das mudanças intencionalmente provocadas por programas como os de "monitoração da competição" (Fuld, 1988), "inteligência competitiva" (FulD, 2007) ${ }^{6}$, "inteligência empresarial"
(SAPiro, 1993). Enfim, programas de "inteligência organizacional e competitiva" (TARAPANOFF, 2001).

A segunda razão é porque, ao buscar descobrir modos eficazes de enfrentar as situações realmente problemáticas, as decisões e as ações são orientadas por informações confiáveis e conhecimentos qualificados que revelam os padrões das relações estruturais e conjunturais das unidades de análise 7 . Unidades essas que permaneciam tácitas, não estavam codificadas, tampouco poderiam ser efetivamente comunicadas e amplamente disseminadas. Tais iniciativas expandem a capacidade e a variedade de requisitos das pessoas, grupos, organizações e sociedades, "tornando o invisível visível" (MARCHAND; Kettinger e Rollins, 2001). Isto é, uma vez "dominando a gestão da informação" (Davenport, Marchand, Dickson, 2004), ocorre uma evolução para o "gerenciamento estratégico da informação” (McGEE E Prusak, 1994). O que credencia as organizações, desta feita, a evoluírem ainda mais para fazerem a "gestão da informação e do conhecimento" (PAIM, 2003), a "gestão estratégica do conhecimento" (FLEURY e Oliveira Jr., 2001). Em resumo, a "gestão do conhecimento na teoria e na prática" (DALKIR, 2005).

A terceira razão é porque, ao enfatizar a importância de intervir na realidade, gerenciando recursos informacionais e aproveitando conhecimentos qualificados no momento de converter decisões em ações, catalisam-se procedimentos qualitativos e quantitativos, teorias, técnicas, melhores práticas, normas, tecnologias, modelos e instrumentos de gestão, que são próprios das disciplinas ou programas supramencionados e de outros que com eles podem convergir para potencializar a capacidade de 
“execução” (Bossidy e Charam, 2005), "fazendo a estratégia funcionar" (HREBINIAK, 2006) produzindo consequências desejáveis.

Realizada a introdução, este artigo passa a ser desenvolvido em seis seções. $\mathrm{Na}$ primeira, são apresentados brevemente dois fundamentos teórico-práticos: fenomenologia e pesquisa-ação. $\mathrm{Na}$ segunda, são tratados aspectos relevantes do contexto. Na terceira, a MSF é destacada como referencial metodológico para desenvolver e aplicar o SIESP. Na quarta seção, são mostradas e operacionalizadas as fases que oferecem suporte às decisões e ações. Na quinta parte, faz-se a conclusão e na sexta é apresentada a bibliografia.

\section{Dois fundamentos teórico-} práticos: fenomenologia e pesquisaação

Para a fenomenologia interessa a experiência vivida no mundo real. Fenomenologia é o estudo dos fenômenos complexos, o que sugere um tratamento multidimensional, transdisciplinar, interrelacional. É uma abordagem apropriada para capturar a essência da experiência interativa humana com os ambientes (Carvalho e Vergara, 2002).

Wilson (2000) destaca que a habilidade de descrever a situação confrontada pelo profissional é uma atividade crucial para analisar corretamente uma dada situação, definir o que nela é importante observar e como nela intervir, com vistas a melhorá-la.

Já a pesquisa-ação (action research) é um método de pesquisa qualitativa que é visto assim por Rappoport (Apud Myers, 1977):

"Action research aims to contribute to the practical concerns of people in an immediate problematic situation and to the goals of social science by joint collaboration within a mutually acceptable ethical framework."

Pesquisadores se baseiam na pesquisaação para desempenhar um papel ativo na realidade dos fatos observados. A estratégia da pesquisa-ação define, de um lado, qual é a ação em questão, quais são os seus agentes, seus objetivos e obstáculos. De

"A situação-problema se modifica com o tempo devido a alterações em suas complexas ramificações, as quais não se revelam imediata e claramente; (...) o problema, diversamente, é um fenômeno evidente logo percebido."

outro lado, define qual é a exigência de informações e conhecimentos a serem obtidos em função dos problemas encontrados (Thiollent, 2002).

O resultado esperado com a adoção da postura descritiva e prescritiva é compreender e interferir na realidade socialmente construída, proporcionando benefícios para as pessoas que nela vivem, trabalham, consomem e produzem. 
Aspectos relevantes do contexto: setor, agência e processo de gestão da informação

Importantes mudanças observadas no setor elétrico brasileiro resultaram da entrada em vigor da Lei $\mathrm{n}^{\circ}$ 8.987, de 13/02/95. Essa Lei foi promulgada para regulamentar e disciplinar as concessões e permissões de serviços públicos, com base no artigo 175 da Constituição Federal. Seu objetivo é dotar o governo de instrumento legal que permita fixar regras gerais para o Estado delegar a terceiros a prestação de serviços públicos.

Já a Lei no 9.427, de 26/12/96, instituiu a Aneel, autarquia sob regime especial, vinculada ao Ministério das Minas e Energia, com a finalidade de mediar interesses, regular e fiscalizar a geração, transmissão, distribuição e comercialização de energia elétrica, em conformidade com a legislação específica, com as políticas públicas e as diretrizes do governo federal. A missão da Aneel é proporcionar condições sistêmicas favoráveis para que o desenvolvimento do mercado de energia elétrica ocorra com equilíbrio entre os agentes, beneficiando a sociedade.

A Agência desenvolve suas atividades com base em processos organizacionais. Processo é qualquer atividade ou conjunto de atividades que toma um insumo, adiciona-lhe valor e fornece resultado a clientes (GonçALVES, 2000). A missão do processo de gestão da informação da Aneel é coletar, tratar, armazenar e disseminar a informação, propiciando agregação de valor na busca do conhecimento e inteligência. Para enfrentar e superar as situações críticas que se interpõem ao cumprimento dessa missão, esse processo organiza-se em 11 subprocessos, conforme mostrado na Figura 1.
Tomando o sentido horário da Figura, a partir do escritório de projetos, a seqüência das tarefas coordenadas pelo processo de gestão da informação é a seguinte:

- Aprova, acompanha, controla, sistematiza, automatiza e avalia projetos, processos e subprocessos que adicionam valor a insumos, produtos, serviços.

- Classifica, organiza, armazena, recupera e facilita o acesso ao acervo bibliográfico, normas e demais registros feitos em diferentes mídias.

- Organiza, armazena, recupera, descarta e facilita o acesso a documentos e a processos administrativos.

- Desenvolve, aperfeiçoa e mantém programas e aplicativos computacionais.

- Armazena dados geográficos que situam no espaço geográfico brasileiro as áreas de interesse das atividades de regulação, mediação e fiscalização da Aneel.

- Implementa e administra bancos de dados.

- Obtém, armazena, atualiza e dissemina informações via internet, intranet e extranet.

- Atualiza equipamentos e os mantém operando continuamente, minimizando a ocorrência de interrupções no acesso e na transmissão dos dados.

- Disponibiliza e gerencia equipamentos de informática, aplicativos e impressão de documentos.

- Presta atendimento aos usuários dos recursos informacionais.

- Propõe, aperfeiçoa e aplica procedimentos e normas de segurança da informação em benefício dos usuários.

O processo de gestão da informação em questão caracteriza-se por tomar recursos informacionais de estoque e de fluxo, adicionar-lhes valor e fornecer produtos e serviços intensivos em 


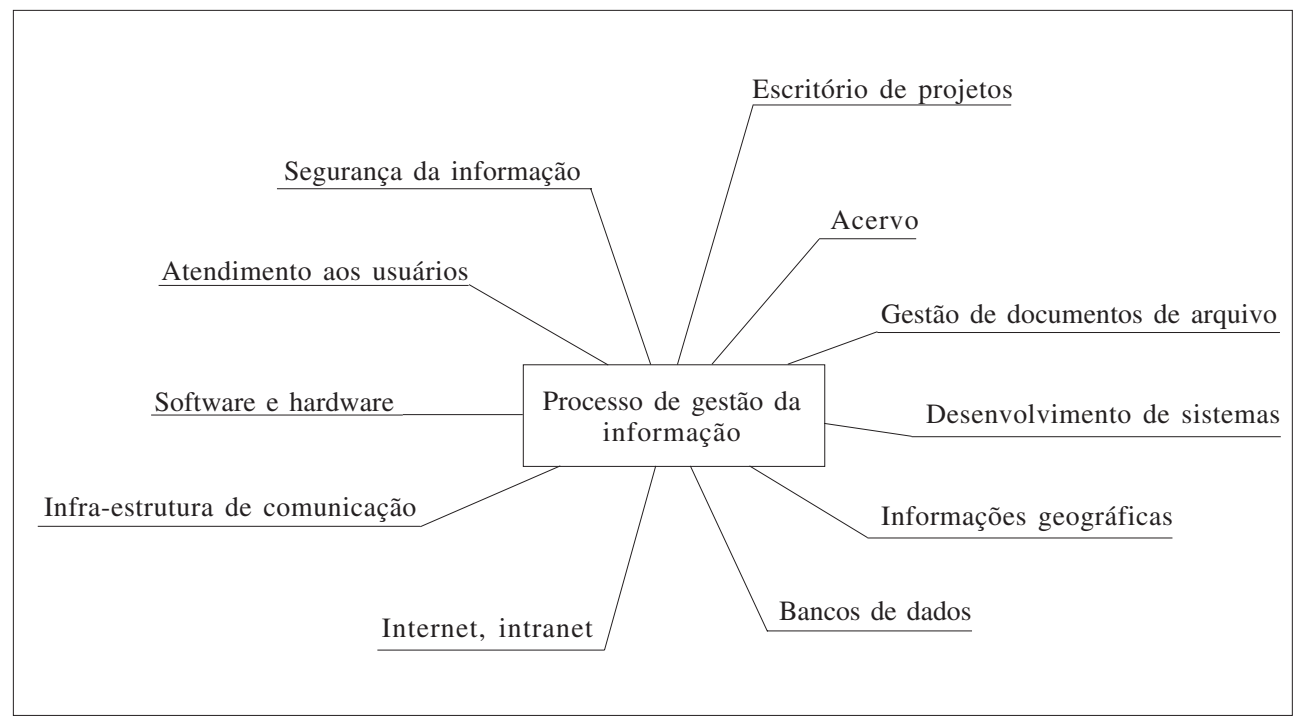

Figura 1: Processo de gestão da informação e seus respectivos subprocessos.

informações confiáveis e em conhecimentos qualificados capazes de satisfazer as necessidades informacionais dos usuários. São esses recursos informacionais que fluem, são armazenados e aproveitados para converter decisões em escolhas e ações legítimas de regulação normativa (resoluções e normas) e executiva (fiscalização e mediação), ocasionando mudanças responsáveis. Em última análise, essas mudanças buscam o desejado equilíbrio, ainda que dinâmico e, portanto, não assegurado, entre oferta e demanda de energia elétrica.

\section{MSF como referencial metodológico}

A MSF é resultado de pesquisas realizadas nos anos 70 por Peter Checkland, professor de systems e de management science da Universidade de Lancaster, Inglaterra. A publicação da primeira edição do livro Systems Thinking, Systems Practice, em 1981, tornou essa metodologia conhecida. Precursores e defensores da MSF argumentam que sistemas rígidos (bard) oferecem respostas condizentes para problemas já estruturados e não exatamente para situações complexas relacionadas a atividades humanas sujeitas a múltiplas interpretações e cercadas de ambigüidades, equivocalidades e incertezas. Diante da realidade que é alterada por causa da dinâmica das contingências ambientais, algumas previsíveis outras não, recorre-se à abordagem flexível (soft). O Quadro 2 compara ambas abordagens.

Abordagens flexíveis, ligadas a pioneiros da teoria geral de sistemas, a exemplo de Ludwig von Bertalanffy, lidam com problemas mal estruturados e estão imbricadas com processos de negociação (Martinelli, 2002).

Por promover a interação social entre os que integram diferentes comunidades de prática existentes numa mesma organização, a aplicação da MSF constitui-se numa oportunidade para chegar a acordos sobre questões como estas: Qual é a situação efetivamente problemática? Como enfrentá-la? Quais resultados produzir? 


\section{Quadro 2: Comparação entre as abordagens hard e soft}

\begin{tabular}{|c|c|}
\hline Abordagem rígida (hard) & Abordagem flexível (soft) \\
\hline $\begin{array}{l}\text { A definição do problema é direta, exigindo a } \\
\text { combinação de conhecimentos explícitos. }\end{array}$ & $\begin{array}{l}\text { A definição da situação-problema é problemá- } \\
\text { tica e pluralista, exigindo a externalização de } \\
\text { conhecimentos implícitos. }\end{array}$ \\
\hline $\begin{array}{l}\text { Organizar é uma condição dada (taken for } \\
\text { granted), assimilada a priori. }\end{array}$ & $\begin{array}{l}\text { Organizar requer negociação e transferência de } \\
\text { conhecimentos que não é imediatamente reali- } \\
\text { zada. }\end{array}$ \\
\hline Modelo é uma representação do mundo real. & $\begin{array}{l}\text { Modelo é uma forma de gerar debate e idéias a } \\
\text { respeito do mundo real proximamente } \\
\text { representado. }\end{array}$ \\
\hline $\begin{array}{l}\text { A abordagem hard de modelagem é fruto do } \\
\text { desenvolvimento da Pesquisa Operacional (PO) } \\
\text { na década de 40, a partir de técnicas como } \\
\text { programação linear, simulação computacional, } \\
\text { teoria das filas, que comungam a premissa de } \\
\text { que um problema é definido e resolvido. }\end{array}$ & $\begin{array}{l}\text { A abordagem soft de modelagem tem origem } \\
\text { na proposta de pesquisadores originalmente } \\
\text { adeptos da abordagem hard. Autores como } \\
\text { Peter Checkland defendem uma nova lógica } \\
\text { (soft) de tratamento para situações proble- } \\
\text { máticas complexas, sugerindo a adoção de um } \\
\text { conjunto de ferramentas que auxiliem o } \\
\text { entendimento da realidade. }\end{array}$ \\
\hline $\begin{array}{l}\text { Orientada por metas. Supõe que a realidade } \\
\text { possui sistemas que podem ser planejados } \\
\text { linearmente. }\end{array}$ & $\begin{array}{l}\text { Orientada pelo aprendizado. Supõe que a rea- } \\
\text { lidade é complexa, embora possa ser explo- } \\
\text { rada por modelos de sistemas, por frameworks. }\end{array}$ \\
\hline $\begin{array}{l}\text { Supõe que os modelos de sistemas representam } \\
\text { os modelos da realidade. Expressa preocupação } \\
\text { e linguagem voltada para problemas e suas } \\
\text { soluções completas e definitivas. }\end{array}$ & $\begin{array}{l}\text { Supõe que os modelos de sistemas são cons- } \\
\text { truções intelectuais. Expressa preocupação com } \\
\text { situações-problema e respostas para tentar } \\
\text { minimizá-las ou superá-las, sem sugerir que a } \\
\text { solução encontrada seja definitiva. }\end{array}$ \\
\hline $\begin{array}{l}\text { O resultado é um produto ou uma reco- } \\
\text { mendação. }\end{array}$ & $\begin{array}{l}\text { O resultado é um progresso obtido pela apren- } \\
\text { dizagem. }\end{array}$ \\
\hline Permite o uso de poderosas técnicas. & $\begin{array}{l}\text { É utilizável por profissionais especializados } \\
\text { integrados com os responsáveis por enfrentar } \\
\text { a realidade das situações-problema. Considera } \\
\text { aspectos humanos na busca de superar as } \\
\text { situações problemáticas críticas. }\end{array}$ \\
\hline $\begin{array}{l}\text { Necessita de profissionais especializados em } \\
\text { técnicas específicas; ignora ou reduz a partici- } \\
\text { pação dos detentores do problema; deixa de } \\
\text { considerar aspectos que transcendem a simples } \\
\text { lógica formal da situação ou do espaço } \\
\text { "decisional". }\end{array}$ & $\begin{array}{l}\text { Não produz respostas definitivas; aceita a idéia } \\
\text { de que o processo de questionamento é } \\
\text { infindável, não-simplista e gerador de conflitos } \\
\text { a serem respeitados para, a partir deles, extrair } \\
\text { lições e formas inovadoras de enfrentar os } \\
\text { desafios. }\end{array}$ \\
\hline
\end{tabular}

Fonte: Wilson (2000; 2001); Checkland (1999); Pidd (1998). 
A MSF serve de referência para fundamentar o Siesp de modo a orientar decisões, cujas conseqüências desejadas são escolhas adequadas, ações legítimas, mudanças responsáveis. Principalmente, as que produzem condições favoráveis para reduzir ambigüidades, equivocalidades e incertezas. Ambigüidade sobre qual é a situação realmente crítica a ser enfrentada prioritariamente. Equivocalidade sobre como fazê-lo de forma tecnicamente consistente, além de coerente com os referenciais estratégicos, culturais (éticos) e técnicos. Incerteza sobre se os resultados esperados serão obtidos com a execução das ações prescritas.

\section{Operacionalização das fases que oferecem suporte às decisões e ações}

A operacionalização das fases indicadas na Figura 2 cria oportunidades para obter informações e expandir conhecimentos sobre a realidade enfocada, para decidir qual é efetivamente a situação-problema antes de agir ponderadamente no sentido de enfrentá-la.

Primeira fase: qual é a situação considerada problemática?

Foram obtidas informações de documentos da Aneel e de reuniões

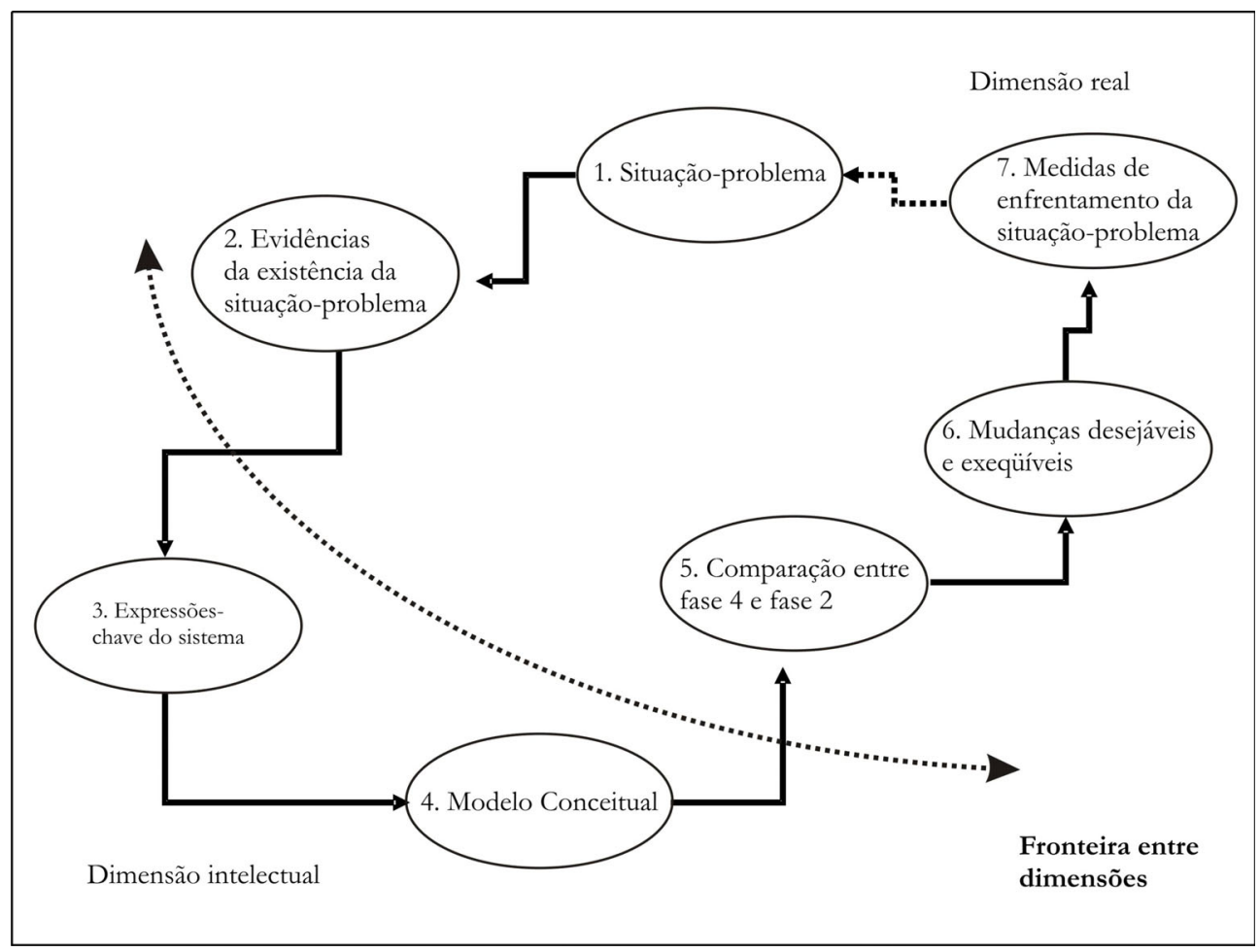

Figura 2: Fases, relações, fronteira e dimensões da MSF. 
formais e informais ocorridas com integrantes dos subprocessos que compõem o processo organizacional encarregado de fazer a gestão do sistema de informação dessa Agência. Tais informações levaram à expansão do conhecimento sobre a realidade e, por conseguinte, ao reconhecimento de que a situação problemática de fundo neste contexto, que pode ser estendida a outros, é a insatisfação informacional dos usuários que se reportam a esse processo organizacional. Seja porque não dispõem ou não obtiveram informações e conhecimentos desejados, seja porque não obtiveram ou não conseguiram operar plena e oportunamente equipamentos, softwares e outros recursos informacionais, de modo a satisfazer-lhes a demanda, além de facilitála e acelerá-la, mediante o aproveitamento adequado e oportuno desses recursos tangíveis e intangíveis.

A demanda informacional pode não ser atendida devido a inúmeras causas. Informações sobre essas causas e o conhecimento necessário para distinguilas e combatê-las efetivamente são um avanço, porque ajudam na boa administração dos recursos informacionais relevantes empregados para enfrentar a situação-problema com eficácia, evitando o erro de atuar sobre efeitos. O cometimento de tal equívoco traz as seguintes conseqüências mais freqüentes: disparo de crises e procura por culpados.

Do lado de quem "puxa" a informação, uma causa, por exemplo, pode ser o desconhecimento da real necessidade informacional ou, no caso de conhecê-la de fato, não conseguir expressá-la de forma compreensível. Do lado de quem "empurra" a informação, uma causa pode ser o desconhecimento do contexto e do uso específico conferido aos recursos requisitados, baixa prioridade em atender as demandas específicas, indisponibilidade material imediata ou mediata de fornecer os recursos demandados.

De um lado ou de outro, o segredo do sucesso no desenvolvimento de sistemas de informação é a compreensão da situação dos usuários, dos problemas associados a essa situação e da correta identficação das informações, dos conhecimentos e dos demais recursos informacionais por eles requeridos. Tais recursos são relevantes justamente porque os auxiliam tanto no momento de decidir, com informações confiáveis, quanto no momento de executar ações, com o aproveitamento do conhecimento qualificado necessário.

\section{Segunda fase: evidências da real existência e importância da situação- problema}

Os questionamentos expressos na coluna da esquerda do Quadro 3 foram extraídos de documentos produzidos pela Aneel. Tais questionamentos evidenciam a real existência da situação-problema, na medida em que sobre ela existem ambigüidades, equivocalidades e incertezas. Em virtude das propriedades emergentes típicas de situações complexas como a insatisfação informacional, não parece razoável admitir sua eliminação e sim sua minimização, com decisões que, uma vez convertidas em ações, promovam a redução da ambigüidade sobre se essa é ou não uma situação-problema real, a redução da equivocalidade sobre como enfrentá-la eficazmente e a redução da incerteza sobre se as ações e as tarefas prescritas produzirão os resultados desejados.

A explicitação da ambigüidade, equivocalidade e incerteza, além de revelar a concretude da situação-problema, sugere 
Quadro 3: Ambigüidades, equivocalidades e incertezas relativas à demanda informacional.

\begin{tabular}{|l|l|}
\hline Questionamento & $\begin{array}{l}\text { - Evidências da existência de ambigüidade, } \\
\text { equivocalidade e incerteza }\end{array}$ \\
\hline "Quais são os produtos de nossas atividades?" & $\begin{array}{l}\text { - Ambigüidade a respeito de quais são os } \\
\text { produtos que atenderão os usuários }\end{array}$ \\
\hline $\begin{array}{l}\text { "Como saberemos se atendemos aos requisitos dos } \\
\text { interessados (usuários)?" }\end{array}$ & $\begin{array}{l}\text { Equivocalidade sobre como gerar produtos } \\
\text { e serviços, atendendo, assim, a demanda } \\
\text { informacional. }\end{array}$ \\
\hline $\begin{array}{l}\text { "Que informação será produzida, compartilhada ou } \\
\text { trocada?" }\end{array}$ & $\begin{array}{l}\text { - Ambigüidade sobre quais informações gerar } \\
\text { e fornecer e sobre quais demandas atender }\end{array}$ \\
\hline $\begin{array}{l}\text { "O que se está fazendo e o que deve ser feito para } \\
\text { implementar dinamicamente a estratégia informacional } \\
\text { com base em princípios, fundamentos, planos e em } \\
\text { ações importantes baseadas em valores éticos que satis- } \\
\text { façam maximamente as necessidades de recursos } \\
\text { informacionais dos usuários e clientes?" }\end{array}$ & $\begin{array}{l}\text { - Equivocalidade sobre o que se está fazendo e } \\
\text { dades informacionais dos usuários. }\end{array}$ \\
\hline
\end{tabular}

Fonte: Plano Estratégico da Informação de 2003 e 2007 (Aneel).

a monitoração constante das informações específicas sobre a demanda por recursos informacionais. Ao buscar, obter, interpretar, avaliar, comunicar e utilizar essas informações, mais esclarecida e estruturada (arquitetada) ficam não apenas a insatisfação informacional específica e real dos usuários, como também os modos mais eficazes e eficientes de minimizá-la oportunamente.

\section{Terceira fase: expressões-chave}

Após distinguir as informações que revelam a existência da situação-problema, principalmente com o aproveitamento do conhecimento do tipo declarativo (knowwhat) assimilado nas fases anteriores, agora algumas expressões-chave são filtradas. Essas expressões resultam do esforço intelectual de explicitar e de registrar aqui o tipo de conhecimento "procedimental" (know-how) necessário para ser possível executar ações importantes. Isto é, ações inteligentes porque produzem conhecimentos sobre as consequências (know-consequence) a serem obtidas com o enfrentamento da situação-problema.

As duas expressões-chave indicadas a seguir são prescritas porque tendem a interferir positivamente na realidade, minimizando a insatisfação informacional. Quando executadas por atores funcionalmente competentes e profissionalmente capacitados, após as consistências dessas ações serem testadas adiante, elas serão utilizadas para elaborar o modelo conceitual da MSF, na fase 4.

- Pesquisar o contexto de atuação profissional dos usuários, suas necessidades informacionais e os usos específicos por eles conferidos aos recursos informacionais demandados ao processo organizacional de gestão da informação.

- Adicionar valor aos recursos informacionais reconhecidamente necessários, validando, recuperando, agrupando, classificando, selecionando, padronizando, atualizando, formatando, sintetizando, facilitando 
e acelerando o acesso e o aproveitamento desses recursos, agora valorizados.

As expressões "pesquisar" e "adicionar valor" sugerem a execução de certas tarefas humanas específicas capazes de contribuir efetivamente para combater as reais causas da insatisfação informacional. A correspondência dessas expressões-chave com a realidade do contexto é testada mediante a aplicação do CATWOE (Quadro 4). Tratase de um processo de geração, confirmação e utilização dos conhecimentos capaz de

\section{Quadro 4: Aplicação do CATWOE}

\begin{tabular}{|c|c|c|}
\hline CA T W O E & Identificação & Comportamentos e atividades \\
\hline $\begin{array}{l}\text { Customers } \\
\text { Quem são? }\end{array}$ & $\begin{array}{l}\text { São os usuários efetivos ou potenciais que } \\
\text { recorrem ou poderão recorrer ao processo de } \\
\text { gestão da informação corporativa para obter } \\
\text { e utilizar recursos informacionais. }\end{array}$ & $\begin{array}{l}\text { Os demandantes buscam recursos informacionais } \\
\text { no processo de gestão da informação, cujos actors } \\
\text { são encarregados de fornecer-lhes, com rapidez, } \\
\text { acurácia e baixo custo. }\end{array}$ \\
\hline $\begin{array}{l}\text { A } \\
\text { Actors } \\
\text { Quem são? }\end{array}$ & $\begin{array}{l}\text { São os profissionais da informação que atuam } \\
\text { no sistema de informação: programadores, } \\
\text { analistas de sistemas, cientistas da informação, } \\
\text { web designers, bibliotecários, arquivistas, outros. }\end{array}$ & $\begin{array}{l}\text { Os actors estão implicados na situação-problema, } \\
\text { no seu reconhecimento e enfrentamento. }\end{array}$ \\
\hline $\begin{array}{l}\text { T } \\
\text { Transform } \\
\text { (Processo de } \\
\text { transformação } \\
\text { dos insumos). }\end{array}$ & $\begin{array}{l}\text { As demandas aparentes (ambíguas) dos } \\
\text { customers são pesquisadas para converterem- } \\
\text { se (transformed) em demandas informacionais } \\
\text { reais claras e legítimas. } \\
\text { As necessidades de informação são então } \\
\text { analisadas para verificar se o seu atendimento } \\
\text { está coerente com os referenciais estratégicos } \\
\text { da organização e do respectivo processo } \\
\text { organizacional, que se transformará em } \\
\text { centro de custos. } \\
\text { A transformação dos recursos informacionais } \\
\text { (inputs) em produtos e serviços de informação } \\
\text { (outputs) é realizada mediante a concretização } \\
\text { das atividades e dos procedimentos destinados } \\
\text { a agregar valor aos produtos e serviços inten- } \\
\text { sivos em informação requeridos pelos } \\
\text { customers oferecidos pelos actors. }\end{array}$ & $\begin{array}{l}\text { Recursos como informação, conhecimento, capaci- } \\
\text { dades e competências, equipamentos, aplicativos } \\
\text { e outros são utilizados/processados (transformed) } \\
\text { pelos actors no sistema de informação da organização, } \\
\text { com vistas a gerar produtos e serviços intensivos em } \\
\text { recursos informacionais que, de fato, satisfaçam as } \\
\text { reais e legítimas demandas informacionais dos } \\
\text { usuários. Basicamente, porque esses produtos e serviços } \\
\text { possuem alto valor agregado. Isto é, permitem que os } \\
\text { usuários informem suas decisões e as convertam em } \\
\text { ações que produzem benefícios individuais, organiza- } \\
\text { cionais e sociais. }\end{array}$ \\
\hline $\begin{array}{l}\text { W } \\
\text { Weltanschaunng } \\
\text { Qual é a visão } \\
\text { preponderante? }\end{array}$ & $\begin{array}{l}\text { Crença de que minimizando a alta ambigüi- } \\
\text { dade, equivocalidade e incerteza, inicialmente } \\
\text { existentes, a insatisfação informacional real } \\
\text { será minimizada, considerando o poder do } \\
\text { dirigente (owner) e as restrições do ambiente } \\
\text { (Environmental constraints). }\end{array}$ & $\begin{array}{l}\text { A demanda informacional estando clara (baixa } \\
\text { ambigüidade), a incerteza e a equivocalidade estando } \\
\text { reduzidas, maior será o êxito em satisfazer as reais } \\
\text { necessidades de informação dos customers. }\end{array}$ \\
\hline $\begin{array}{l}\text { O } \\
\text { Owner } \\
\text { Quem é o dirigente? }\end{array}$ & $\begin{array}{l}\text { Responsável pelo processo de gestão da } \\
\text { informação corporativa. Principal responsável } \\
\text { pelo sistema de informação da organização. }\end{array}$ & $\begin{array}{l}\text { Confere ou não condições facilitadas para que o } \\
\text { sistema de informação aperfeiçõe suas atividades, } \\
\text { priorize certos projetos, tornando seus colaboradores } \\
\text { (actors) mais capacitados a converter inputs em } \\
\text { produtos e serviços (outputs) com alto valor agregado } \\
\text { antes de serem ofertados aos } 34 \text { customers. }\end{array}$ \\
\hline $\begin{array}{l}\text { E } \\
\text { Environmental } \\
\text { Constraints } \\
\text { (Restriçoes do ambiente } \\
\text { a serem consideradas). }\end{array}$ & $\begin{array}{l}\text { Variáveis externas insuscetíveis de controle } \\
\text { pelo owner e actors. O comportamento } \\
\text { dessas variáveis independe das atividades } \\
\text { humanas realizadas na organização. }\end{array}$ & $\begin{array}{l}\text { Mudança dos (nos) agentes setoriais e nos segmentos } \\
\text { do macroambiente; contingenciamento orçamentário; } \\
\text { alterações constantes do modelo de intervenção } \\
\text { setorial; vulnerabilidade à ocorrência de secas; elevação } \\
\text { abrupta do consumo de energia elétrica; política de } \\
\text { investimentos restritiva; processo de licitação moroso; } \\
\text { cargos de diretores vagos; insuficiência de pessoal } \\
\text { experiente; pouco tempo para pesquisar e agregar valor } \\
\text { aos recursos informacionais. }\end{array}$ \\
\hline
\end{tabular}


distinguir os elementos relevantes do contexto sob exame; especificamente, os usuários (customer) (C), atores (actors) (A), as transformações $(T)$ decorrentes das intencionalidades, a visão (weltanschaunng) (W) que orienta ações e comportamentos, o dono (owner) (O) ou administrador dos recursos e as restrições do ambiente (environmental constraints) (E).

\section{Quarta fase: modelo conceitual}

O modelo conceitual mostrado na Figura 3 representa graficamente as infor- gência organizacional e competitiva, o que fez reduzir a ambigüidade sobre qual é a situação-problema.

- a descoberta das ações que ajudam a enfrentá-la (fases 3, 4, 5 e 6), mediante a prática da gestão do conhecimento na teoria e na prática, o que resultou em redução da equivocalidade sobre como agir e coordenar ações que minimizem a insatisfação informacional.

- a distinção das tarefas a executar à luz dos referenciais estratégicos, as quais

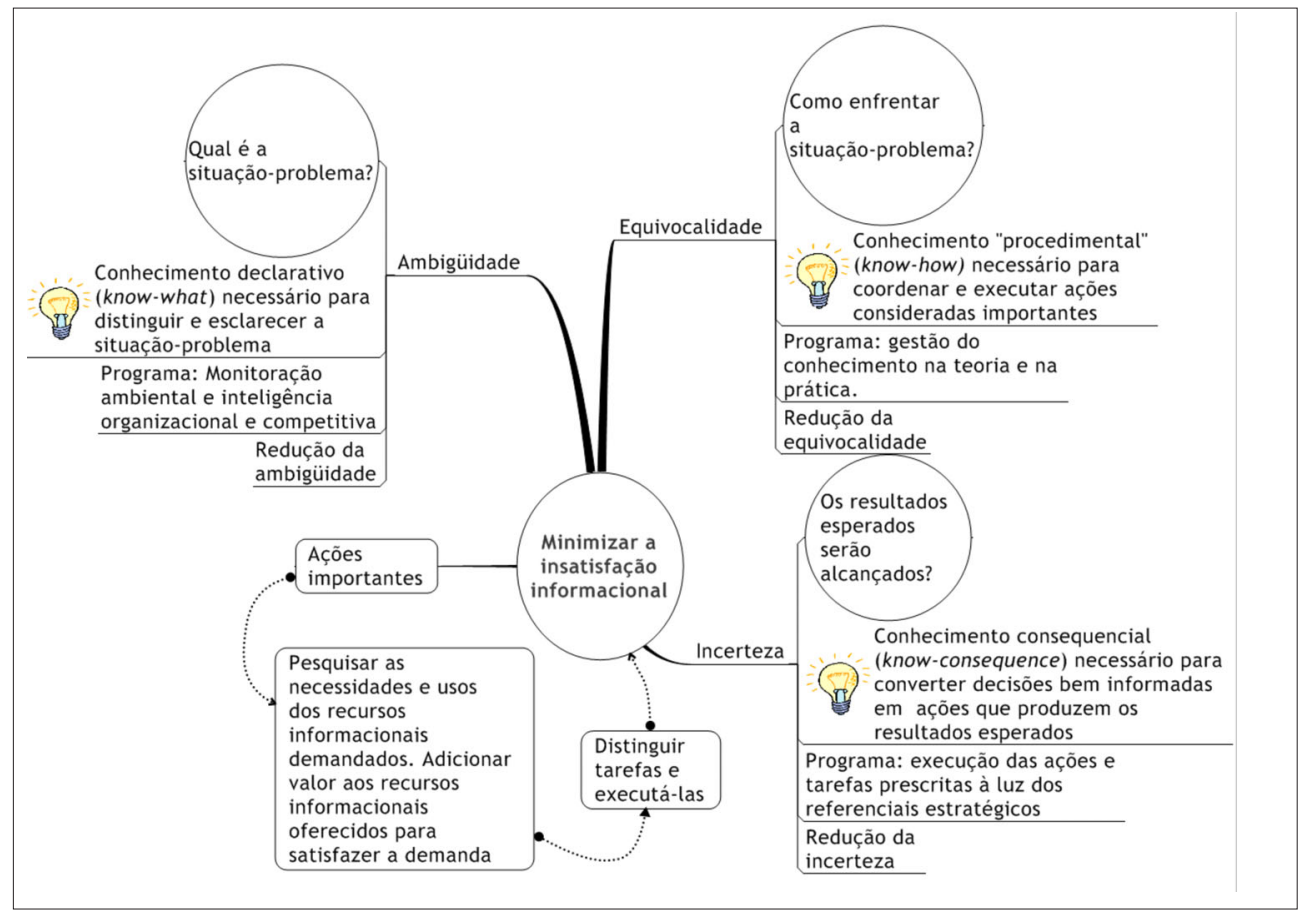

Figura 3: Modelo Conceitual.

mações e os conhecimentos assimilados até esta fase 4 da MSF. É construído como resultado da expansão e da explicitação do conhecimento sobre o contexto. Em particular, esse modelo evidencia:

- a distinção e o esclarecimento da situação-problema (fases 1 e 2), mediante a prática e o uso de instrumentos das disciplinas monitoração ambiental e inteli- tendem a reduzir a incerteza sobre se os resultados esperados serão alcançados.

A ação de pesquisar associa-se à de adicionar valor para transformar (transform) demandas por recursos informacionais desconhecidas e/ou insatisfeitas em produtos e serviços bem definidos e que serão gerados pelos atores (actors) no processo de gestão da 
informação corporativa, de modo a satisfazer a demanda real dos usuários (customers).

A visualização da informação e do conhecimento explicitados na Figura 3, conforme registrado na introdução deste trabalho, busca registrar e facilitar a compreensão dos conhecimentos que antes eram mantidos tácitos, não codificados e não disseminados e que, agora, representados na forma gráfica, torna o invisível visível, ajudando a explicitar ações que, uma vez executadas, minimizam a insatisfação informacional.

\section{Quinta fase: modelo conceitual versus situação-problema}

As informações e os conhecimentos expressos no modelo conceitual (Figura 3, fase 4), uma vez assimilados, tratados, administrados e aproveitados na conversão das decisões informadas em ações, serão eficazes no enfrentamento da situaçãoproblema caracterizada nas fases 1 e 2? Esse questionamento estimula reflexões sobre se as mudanças ocasionadas pelas ações são eficazes para minimizar a insatisfação informacional.

A operacionalização desta quinta fase produz, portanto, as oportunidades para estabelecer diálogo, debate entre especialistas e não-especialistas, convergir diferentes pontos de vista e operar instrumentos de gestão destinados a fazer emergir tarefas que se entendam eficazes para minimizar a insatisfação informacional.

\section{Sexta fase: mudanças ocasionadas pelo desdobramento das ações em tarefas}

As mudanças desejadas decorrerão da execução das ações importantes de pesquisar as necessidades e os usos dos recursos informacionais e de adicionar valor a esses recursos antes de fornecê-los aos usuários. O desdobramento dessas ações nas tarefas que emergiram da dinâmica operada na fase 5 da MSF resultou da prática dos seguintes programas:

- De monitoração ambiental e inteligência organizacional e competitiva, com vistas a levantar novas informações e ampliar o conhecimento sobre o contexto.

- De gestão da informação e do conhecimento na teoria e na prática, com vistas a explicitar, registrar e representar conhecimentos.

- De execução das ações e das tarefas aqui prescritas à luz dos referenciais estratégicos (missão da Aneel e do processo organizacional de gestão da informação) e de outros condicionamentos ambientais (política, orçamento, licitação, pessoal).

\section{Sétima fase: execução para fazer a estratégia funcionar}

Nesta última fase são apresentadas as tarefas derivadas das ações importantes que logram minimizar a insatisfação informacional.

1) Classificar e mapear as informações e os conhecimentos relevantes, facilitando a visualização e, portanto, a compreensão da importância desses recursos, de modo a expressar claramente aspectos relevantes do sistema de informação da organização. Particularmente, os seguintes aspectos da demanda e da oferta dos recursos informacionais:

1.1. Do lado dos usuários (demanda): suas reais necessidades informacionais e os usos por eles (habitualmente) conferidos aos recursos informacionais demandados nas suas respectivas áreas específicas de trabalho ou campo de exercício das suas respectivas capacidades profissionais e competências funcionais. 
1.2. Do lado dos que ofertam recursos informacionais: as capacidades analíticas, sintéticas e pragmáticas que eles têm de desenvolver e dominar, bem como os instrumentos de gestão e outras tecnologias e disciplinas que eles têm de empregar para auxiliá-los no trabalho contínuo de minimizar sua insatisfação informacional e a de terceiros.

2) Desenvolver a visão sistêmica, enfatizando a importância de distinguir causas de efeitos, meios de fins, atividades intermediárias de finalísticas, partes de um todo, o essencial do acessório, situaçõesproblema de problemas, além dos referenciais estratégicos, culturais (éticos) e técnicos e, ainda, as restrições existentes no ambiente (contexto interno e externo à organização).

3) Configurar subprocessos organizacionais que sejam próximos das comunidades de prática, facilitando o fluxo dos conhecimentos qualificados entre suas fronteiras formal e informalmente constituídas. Especialmente, os conhecimentos qualificados sobre melhores práticas, procedimentos, padrões e normas técnicas, de modo a fortalecer a relação de interdependência sociotécnica dos trabalhos destinados a minimizar a insatisfação informacional.

4) Incentivar a formação de comunidades de prática por meio das quais possam ser compartilhados e aproveitados conhecimentos necessários para desenvolver projetos priorizados por uma comissão de gestão da informação de caráter corporativo.

5) Recompensar e prestigiar o comportamento informacional daqueles que colaboram para facilitar o compartilhamento e o trânsito facilitado e ágil do conhecimento, bem como a prática da pesquisa e a de adicionar valor aos recursos informacionais antes deles serem fornecidos aos usuários $e$, conseqüentemente, por eles utilizados.

6) Treinar o pessoal para dominar e praticar as disciplinas indicadas neste trabalho, utilizar seus respectivos instrumentos de gestão, adotando metodologias de natureza sistêmica, a exemplo das mencionadas na introdução deste trabalho, bem como o Siesp.

7) Realizar estudos que expressem o grau de insatisfação informacional dos

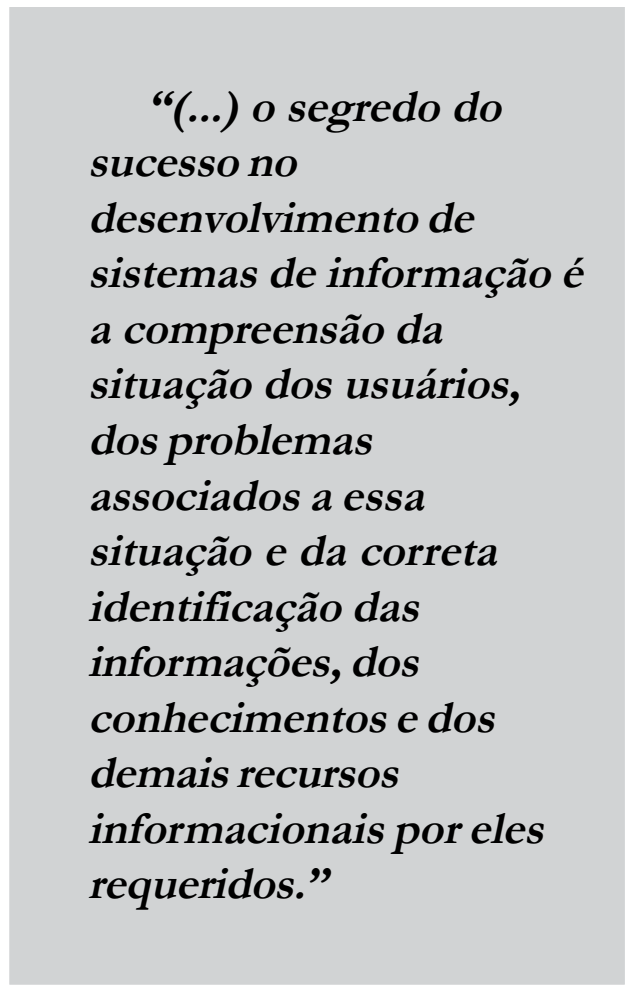

usuários, com vistas a avaliar o comportamento desse indicador ao longo do tempo e a eficácia das ações a serem prescritas e adotadas pelos técnicos que atuam nos sistemas de informação das organizações.

\section{Conclusão}

No contexto enfocado, o Siesp mostrou-se um recurso multifacetado, 
inclusivo, sistêmico e efetivamente útil em termos tanto estratégicos quanto gerenciais. Em termos estratégicos, porque, ao orientar o trabalho de distinção de situações-problema, a exemplo da insatisfação informacional dos usuários do sistema de informação da Aneel, reduz a ambigüidade sobre se uma dada situação é ou não realmente problemática, o que ajuda a descrever e a endossar, portanto, a legitimar os referenciais estratégicos que orientarão as decisões críticas.

Sob o aspecto gerencial, esse suporte mostrou-se útil porque, ao orientar o trabalho de fazer emergir ações importantes, a exemplo das que aqui foram prescritas para enfrentar a situação enquadrada como problemática, reduz a equivocalidade sobre como enfrentá-la. Isso ajuda, de um lado, a direcionar responsavelmente energias, esforços, dinheiro, instrumentos de gestão, conhecimentos, informações e demais recursos informacionais que se complementam para realizar o trabalho sociotécnico de executar, eficaz e eficientemente, as ações prescritas. De outro lado, ajuda a reduzir a incerteza sobre se tais ações produzirão os resultados esperados, como o de minimizar a insatisfação informacional dos legítimos usuários do sistema de informação organizacional.

A visualização dos tipos de conhecimento representados na Figura 4 busca, enfim, facilitar a compreensão dos conhecimentos que são importantes e antes

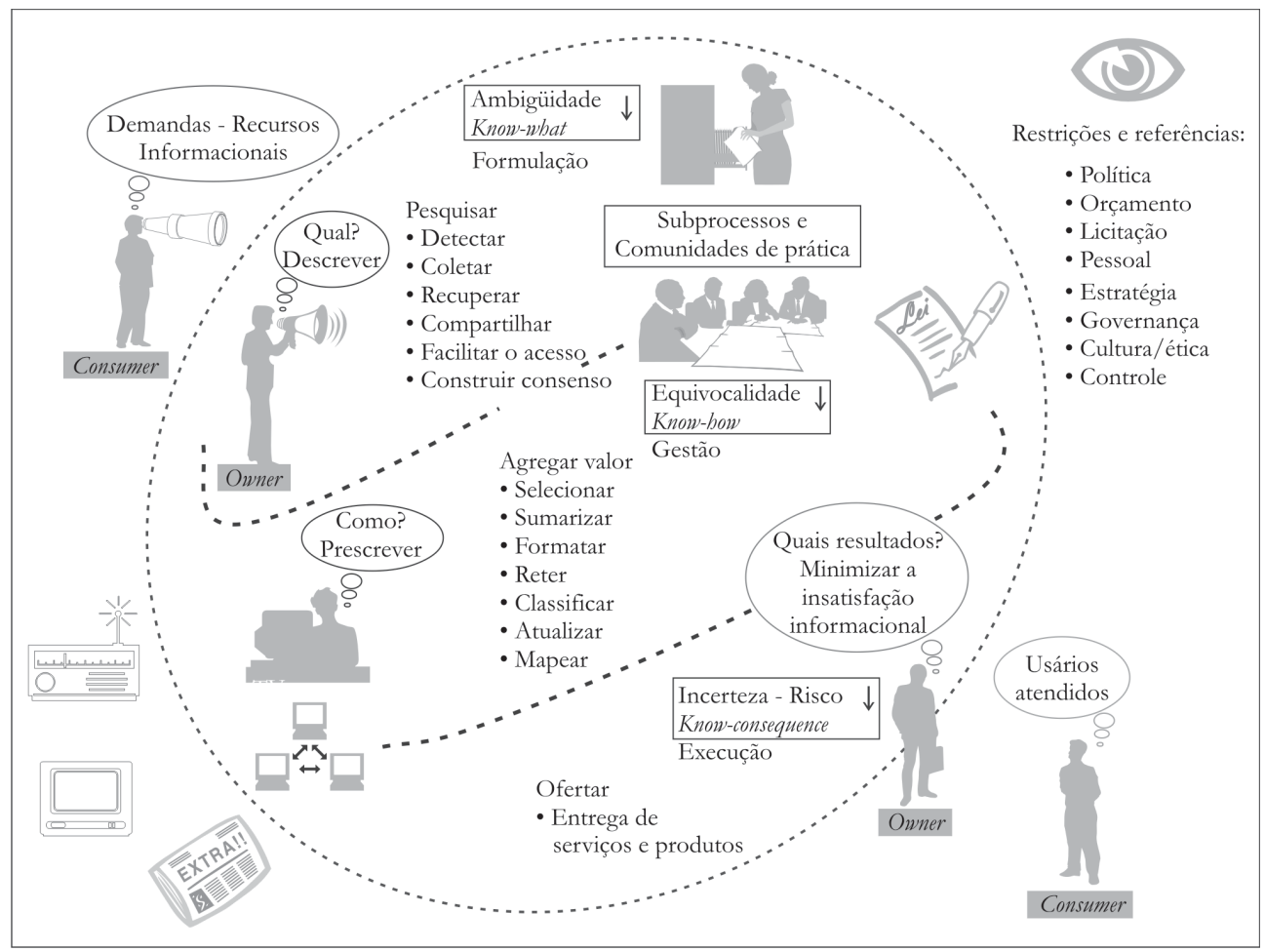

Figura 4: Sistema de gestão das informações orientado para minimizar a insatisfação informacional dos usuários. 
permaneciam tácitos devido à ambigüidade, à equivocalidade e à incerteza.

Estudos futuros poderão ser realizados para aplicar, testar e aperfeiçoar o Siesp em outros contextos organizacionais, o que poderá fazer esse recurso evoluir para constituir instrumento de efetivo apoio na identificação e no enfrentamento de situações-problema.

(Artigo recebido em 28 de janeiro de 2008. Versão final em 24 de março de 2008).

\section{Notas}

1 "Pensamento sistêmico é um quadro de referência conceitual, um conjunto de conhecimentos e ferramentas desenvolvido ao longo dos últimos cinqüenta anos para esclarecer os padrões como um todo e ajudar-nos a ver como modificá-los efetivamente" (Peter Senge. A quinta disciplina. SP: Ed. Best Seller, 1999, p.40-41).

2 Sistema de informação organizacional é um ambiente organizado e estruturado para alcançar objetivos específicos relacionados à informação e composto de pessoas, equipamentos e procedimentos (Debons e Montgomery. Design and evaluation of information systems. ARIST, v. 09, 1974).

3 Visualização da informação é um instrumento de exploração visual que capacita o usuário a interagir com o conteúdo visualizado e a compreender seu significado (Chaomei Chen. Top 10 unsolved information visualization problems. Computer Graphics and Applications, IEEE v. 25, issue 4, July-Aug. 2005 p. 12-16). Visualização do conhecimento é o uso de representações visuais para aperfeiçoar a transferência e a criação do conhecimento entre, no mínimo, duas pessoas (Remo Burkhard. Knowledge vizualization. Dissertation submitted to the Swiss Federal Institute of Technology Zurich, 2005).

4 O termo "recursos informacionais" inclui informação e demais recursos como pessoal, equipamento, fundos e tecnologia da informação. Trata-se de uma abordagem que inclui "planejar, organizar, custear, alocar, monitorar e controlar pessoas, fundos e tecnologias, bem como as atividades associadas a obter, armazenar, processar e distribuir dados e atender necessidades de negócio que beneficiem a corporação inteira" (Snyder e Rainer. Journal of management information systems, v.12, n.1, 1985, p.199-223).

5 Wenger e Snyder (Communities of practice: the organizational frontier. HBR, JanuaryFebruary, 2000, p.139-145). Para uma revisão da literatura: Davenport e Hall em Organizational knowledge and communities of practice (ARIST, v. 36, 2002).

6 Para Fuld, "inteligência é usar informação de forma eficiente e tomar decisões com uma imagem menos do que perfeita" (2007, p.16).

7 Unidades de análise variam bastante. A "Social Network Analysis - SNA", por exemplo, é um recurso útil para estudá-las, pois busca evidenciar estruturas e dinâmicas de relacionamento existentes entre as unidades de análise. Fluxos e arquiteturas revelam padrões que ampliam o conhecimento sobre os mesmos, elevando a capacidade teórica e prática. 


\section{Referências bibliográficas}

Alavi, Maryam; LeIDnER, D. Knowledge management and knowledge management systems. MIS Quarterly, v.25, n.1, p.107-136, 2001.

Barbosa, Ricardo R. Monitoração ambiental: uma visão interdisciplinar. Revista de Administração, v.32, n.4, p.42-53, outubro/dezembro, 1997.

Bossidy, Larry; Charam, Ram. Execução. RJ: Elsevier, 2005.

Brasil. Agência Nacional de Energia Elétrica - ANEEL. Planejamento estratégico da informação. Brasília: ANEEL, SGI, 2003 e 2007.

Brunsson, Nils. The consequences of decision-making. New York: Oxford University Press, 2007. Carvalho, José L. Felício e VERGARA, Sylvia Constant. A fenomenologia e a pesquisa dos espaços de serviços. RAE, v. 42, n.3, p.78-91, jul./set., 2002.

Checkland, Peter. System thinking, systems practice. Chichester: John Wiley \& Sons, 1999. Choo, Chun Wei. A organização do conbecimento. SP: Ed. SENAC, 2003.

DaLKIR, Kimiz. Knowledge management in theory andpractice. Burlington: Elsevier ButterworthHeinemann, 2005.

Dann, Zoë; Barclay, Ian. Complexity theory and knowledge management application. The Eletronic Journal of Knowledge Management, v.4, issue 1, p.11-21, 2006.

Davenport, Thomas; Marchand, Donald; Dickson, T. Dominando a gestão da informação. Porto Alegre: Bookman, 2004.

Fleury, Maria Tereza; OliveIra JR, M (Orgs.). Gestão estratégica do conhecimento. SP: Atlas, 2001.

Forcadell, F; Guadamillas, F. A case study on the implementation of a knowledge management strategy oriented to innovation. Knowledge and Process Management, v. 9, n.3, p.162-171, 2002.

Fuld, Leonard M. Monitoring the competition. Chichester: John Wiley \& Sons, 1988. . Inteligência competitiva. RJ: Elsevier, 2007.

GonçALVES, José E. Lima. As empresas são grandes coleções de processos. RAE, v. 40, n.1, p.6-19, jan./mar., 2000.

Grant, Robert M. Contemporary strategy analysis. Oxford: Blackwell Publishing, 2005.

Hrebiniak, Laurence G. Making strategy work. NJ: Whaton School Publishing, 2005.

Kasper, H. Perspectivas em pensamento sistêmico. Andrade, Aurélio et al. Pensamento sistêmico. Porto Alegre: Artmed Editora, 2006.

Marchand, Donald; Kettinger, W.; Roldins, J. Making the invisible visible. Chichester: John Wiley \& Sons, 2001.

Martineldi, Dante P. Negociação empresarial. SP: Manole, 2002.

McGeE, James; PRUSAK, L. Gerenciamento estratégico da informação. RJ: Campus, 1994.

Myers, Michael D. Qualitative research. Disponível em http://www.qual.auckland.ac.nz/. Acesso realizado em 25 de abril de 2007. 
NonAKa, Ikujiro. A dynamic theory of organizational knowledge creation. Organization Science, v.5, n.1, February, 1994.

NovAK, Jasminko. Helping knowledge cross-boundaries: using knowledge visualization to support cross-community sensemaking. Proceedings of the $40^{\text {th }}$ Hawaii International Conference on System Sciences, 2007.

PAim, Isis (Org.). A gestão da informação e do conhecimento. BH: Escola de Ciência da Informação - UFMG, 2003.

PIDD, M. Modelagem empresarial. Porto Alegre: Artmed Editora, 1998.

Ritchie-Dunham, James L. e RabBino, Hal T. Managing from clarity. Chichester: John Wiley \& Sons, 2001.

Rubenstein-Montano, R. et al. A systems thinking framework for knowledge management. Decision Support Systems, v.31, 2001, p.5-16.

SAPIRO, Arão. Inteligência empresarial. RAE, v.33, n.3, p.106-124, Mai/Jun. 1993.

TARAPANOFF, Kira (Org.). Inteligência organizacional e competitiva. Brasília: Editora Universidade de Brasília, 2001.

Thiollent, Michel. Metodologia da Pesquisa-ação. SP: Cortez, 2002.

Wilson, Brian. Soft Systems Methodology. Chichester: John Wiley \& Sons, LTD, 2001. . Systems: concepts, methodologies, and applications. Chichester: John Wiley \& Sons,

2000. 


\section{Resumo-Resumen-Abstract}

\section{Suporte de identificação e enfrentamento de situações-problema (Siesp) Pedro Paulo Costallat Bruno}

Desenvolve e aplica o Suporte de Identificação e Enfrentamento de Situações Problema (Siesp). Sob o ponto de vista descritivo, esse recurso busca ampliar e explicitar informações sobre situaçõesproblema existentes nas organizações, mas que não são facilmente percebidas. Sob o ponto de vista prescritivo, esse Suporte baseado na Metodologia de Sistemas Flexíveis (MSF) busca ampliar e explicitar conhecimentos a serem aproveitados para converter decisões bem informadas em ações oportunas de confronto da situação antes enquadrada como problemática, porque ela causa ou tem potencial para causar consequências indesejáveis. O contexto focalizado é o sistema de informação da Agência Nacional de Energia Elétrica (ANEEL). O resultado desse trabalho é relatado neste artigo. Novos trabalhos poderão ser realizados com o propósito de aplicar o SIESP em outras realidades organizacionais, com vistas a consolidá-lo como recurso útil destinado a ampliar, explicitar e aproveitar conhecimentos.

Palavras-chave: informação, conhecimento, decisão, situação-problema, MSF.

\section{Soporte de identificación y afrontamiento de situaciones-problema (Siesp) Pedro Paulo Costallat Bruno}

Desarrolla y aplica el Soporte de Identificación y Afrontamiento de Situaciones Problema. Desde el punto de vista descriptivo, ese recurso intenta ampliar y explicitar informaciones respecto a situaciones problema que existen en las organizaciones pero que no son muy fácilmente percibidas. Desde el punto de vista prescriptivo, ese Soporte basado en la Metodología de Sistemas Flexibles (MSF) intenta ampliar y explicitar conocimientos que van a ser aprovechados para convertir decisiones bien informadas en acciones oportunas de confrontación de la situación antes considerada problemática, porque causa o tiene potencial para causar consecuencias indeseables. El contexto focalizado es el sistema de información de la Agencia Nacional de Energía Eléctrica. El resultado de ese trabajo es relatado en este artículo. Otros trabajos podrán ser realizados con el propósito de aplicar el Soporte em otras realidades organizacionales, con el objetivo de consolidarlo como recurso útil destinado a ampliar, explicitar y aprovechar conocimientos.

Palabras clave: informatión, conocimiento, decisión, situación problema, MSF.

\section{Support of identification and confrontation of problem-situations (Siesp) Pedro Paulo Costallat Bruno}

Develops and applies the Support of Identification and Confrontation of Problem-Situations. Under the descriptive point of view, this resource intends to amplify and explicit information about problematic situations that exist in organizations, but that are not perceived easily. Under the prescriptive point of view, this support based on Soft System Methodology (SSM) amplifies and explicits a knowledge used to convert informed decisions into opportune actions to confront those situations squared before as problematic because they cause or have potential to cause undesirable consequences. The specific context in focus is the information system of National Electric Energy Agency. The result of this work is reported in this article. Other works can be done with the purpose to apply this Support in other organizational realities in order to consolidate it as a valuable resource to amplify, explicit and exploit knowledge.

Keywords: information, knowledge, decision, problem-situation, SSM.

Pedro Paulo Costallat Bruno é mestre em Ciência da Informação pela Universidade Federal de Minas Gerais; Bacharel em Economia pela Universidade de Brasília.

Contato: pbruno@aneel.gov.br 